\title{
Corn Husk Fiber-Polyester Composites as Sound Absorber: Nonacoustical and Acoustical Properties
}

\author{
Nasmi Herlina Sari, ${ }^{1}$ I. N. G Wardana, ${ }^{2}$ Yudy Surya Irawan, ${ }^{2}$ and Eko Siswanto ${ }^{2}$ \\ ${ }^{1}$ Department of Mechanical Engineering, Faculty of Engineering, Mataram University, Nusa Tenggara Barat, Indonesia \\ ${ }^{2}$ Department of Mechanical Engineering, Faculty of Engineering, Brawijaya University, East Java, Indonesia \\ Correspondence should be addressed to Nasmi Herlina Sari; n.herlinasari@unram.ac.id
}

Received 13 December 2016; Accepted 29 January 2017; Published 19 February 2017

Academic Editor: Marc Thomas

Copyright (c) 2017 Nasmi Herlina Sari et al. This is an open access article distributed under the Creative Commons Attribution License, which permits unrestricted use, distribution, and reproduction in any medium, provided the original work is properly cited.

\begin{abstract}
This study investigates the acoustical and nonacoustical properties of composites using corn husk fiber (CHF) and unsaturated polyester as the sound-absorbing materials. The influence of the volume fraction of CHF on acoustic performance was experimentally investigated. In addition, the nonacoustical properties, such as air-flow resistivity, porosity, and mechanical properties of composites have been analyzed. The results show that the sound absorptions at low frequencies are determined by the number of lumens in fiber, particularly the absorption coefficient, which increases the amount of fiber. For high-frequency sound, the absorption coefficient is determined by the arrangement of fibers in the composite. An absorption coefficient is close to zero when the fibers are arranged in a conventional pattern; however, when they are arranged in a random pattern, a high absorption coefficient can be obtained. The bond interface between the fiber and resin enhances its mechanical properties, which increases the longevity of the composite panel.
\end{abstract}

\section{Introduction}

Noise pollution and waste management are two problems that need to be solved in modern societies. The use of newly developed alternative materials to absorb the noise considerably minimizes these problems. Hence, the inexpensive, easily created, thin, and lightweight composite materials that can absorb sound waves in broader frequency fields are highly desirable.

The fibrous sound-absorbing materials have been extensively investigated [1-5]. Biot studies $[1,2]$ provide an approach for the propagation of elastic waves in the fluid medium-saturated porous material at high and low frequencies, where factors such as pore geometry, fluid, and medium having comparable densities are required to be considered. Delany and Bazley [3] developed a simple model for estimating the sound of absorption coefficients and characteristics of impedance of different types of fibrous absorbent materials. Lee and Chen [4] developed Acoustic Transmission Analysis (ATA) model to estimate the acoustic absorption of a multilayer absorbers. Attenborough [5] developed a model for estimating the acoustical characteristics of fibrous absorbents soils and sands using flow resistivity formulae.

The polymer has been widely utilized as a matrix in fiber composites because it is easily formed from a material that has physical and acoustical properties [6-13]. Veerakumar and Selvakumar [6] studied acoustic properties for composite made from kapok fiber with polypropylene fiber, which were found to demonstrate good sound absorption behavior in the frequency range $250-2000 \mathrm{~Hz}$. Jailani et al. [7] studied on panels made from coconut coir fibers which have been conducted to analyze compression effect of the panel on the acoustic performance. The coir fiber panel is a good sound absorber at $1.5-5 \mathrm{kHz}$. Zulkifli et al. [8] investigated the effect of the porous layer backing and a perforated panel on the sound absorption coefficient of coconut coir fiber. They indicated that increasing the thickness material of the panel will improve the sound absorption ability, especially in the low-frequency range at $600-2400 \mathrm{~Hz}$. Chen et al. [9] studied the sound-absorbing properties of ramie fiber-reinforced polylactic acid materials. Putra et al. [10] studied the potential of waste fibers from paddy mixed with polyurethane as 
acoustic material and found that the absorption coefficient is greater than 0.5 from $1 \mathrm{kHz}$ and can reach the average value of 0.8 above $2.5 \mathrm{kHz}$. Bastos et al. [11] developed vegetable fibers: coconut, palm, sisal, and aca1 as soundabsorbing panels. Measurement scale reverberation chamber exposed promising results from acoustic performance for all panels. Flammability, odor, fungal growth, and aging tests have been performed on samples to identify their practical ability. Koizumi et al. [12] developed bamboo fiber as sound-absorbing material. They reported that the bamboo fiber material has equivalent acoustics properties with glass wool. Jayamani and Hamdan [13] studied sound absorption coefficient of urea-formaldehyde and polypropylene mixed with kenaf fiber. They reported that the kenaf fiber reinforced with polypropylene demonstrates higher sound absorption coefficients than kenaf fiber reinforced with ureaformaldehyde. These previous studies represented that a better understanding of the microstructure and physical parameters of a material could help in developing highperformance acoustic materials.

This study primarily investigates the effect of adding corn husk fibers (CHFs) on acoustical and nonacoustics properties of polyester composites. In addition, the effects of fiber content on the tensile properties and microstructures via SEM have been analyzed. The results of this study could contribute to engineering applications, especially as sound absorbers.

\section{Materials and Methods}

2.1. Materials and Sample Preparation. CHF is the main raw material used in this study. The fiber contains $46.15 \%$ cellulose, 33.79\% hemicellulose, and 3.92\% lignin. It has been treated with $5 \%$ sodium hydroxide $(\mathrm{NaOH})$ for $2 \mathrm{~h}$. The scheme of reaction is given as follows:

$$
\mathrm{CHF}-\mathrm{OH}+\mathrm{NaOH} \longrightarrow \mathrm{CHF}-\mathrm{O}-\mathrm{Na}^{+}+\mathrm{H}_{2} \mathrm{O}
$$

Chemical reactions have been removing impurities on the fiber surface. The CHF was rinsed five times with mineral water in other to remove $\mathrm{NaOH}$ sticking from the fiber surfaces. They were dried in natural sunlight to remove any residual moisture and were then preserved in a dry box with a humidity of $40 \%$. The chemical contents of treated $\mathrm{CHF}$ are $54.37 \%$ cellulose, $22.37 \%$ hemicellulose, and 5.64\% lignin. The average of diameter of a single CHF is $0.133 \pm 0.03 \mathrm{~mm}$, measured by a Mitutoyo digital micrometer.

The unsaturated polyester resin $2250 \mathrm{BW}$-EX has a viscosity of $6-8$ poise $\left(25^{\circ} \mathrm{C}\right)$, the tensile strength of $8.8 \mathrm{Kg} / \mathrm{mm}^{2}$, a tensile modulus of $500 \mathrm{Kg} / \mathrm{mm}^{2}$, the flexural strength of $2.5 \mathrm{Kg} / \mathrm{mm}^{2}$, and elongation of $2.3 \%$.

The weight of polyester resin and CHFs were measured before processing so as to determine the volume fraction of CHFs and polyester in the resulting composite. The composition of different sound absorbers is summarized in Table 1 . The mixtures were hot pressed at $100^{\circ} \mathrm{C}$ and $0.3 \mathrm{MPa}$ for $4 \mathrm{~min}$ into a round mold with a diameter of $32 \mathrm{~mm}$, followed by cooling to room temperature at $5 \mathrm{MPa}$ to obtain a round shape to fit in the impedance tube during the sound
TABLE 1: The composition of the composite (mean values in volume fraction).

\begin{tabular}{lcc}
\hline Sample & CHF (\%) & Polyester resin (\%) \\
\hline PF-E & 20 & 80 \\
PF-G & 40 & 60 \\
PF-H & 50 & 50 \\
PF-I & 60 & 40 \\
PF-K & 70 & 30 \\
PF-M & 80 & 20 \\
\hline
\end{tabular}

absorption test. All the absorber materials were obtained with a diameter of $29 \mathrm{~mm}$ and thickness of $20 \mathrm{~mm}$. Six different samples were used for acoustical and porosity tests.

2.2. Porosity. The connected porosity of composite sample was nonacoustically measured using the method of water saturation used by Vašina et al. [14]. All the samples were dried at $105^{\circ} \mathrm{C}$ for $24 \mathrm{~h}$. Subsequently, they were weighed before being left in a vacuum vessel to saturate under water; the density of water is $\rho_{w}=1000 \mathrm{Kg} \cdot \mathrm{m}^{-3}$. After $24 \mathrm{~h}$, they were carefully removed and weighed again. The porosity was computed using $\varepsilon=V_{a} / V_{s}$, where $V_{a}$ is the volume of the composite occupied by the water and $V_{s}$ is the total volume of the composite. The volume of water can be computed using $V_{w}=\left(m_{2}-m_{1}\right) / \rho_{w}$, where $m_{2}$ and $m_{1}$ are the wet and the dry masses of the composite $(\mathrm{Kg})$, respectively.

2.3. Air-Flow Resistivity. There are several empirical and semiempirical equations in the literature that can be used to estimate the flow resistivity of absorber materials based upon fiber radius and material porosity or the bulk density of the materials [14-16]. The air-flow resistivity of the samples used in this study is expressed in [16]

$$
R=\frac{6.8 \mu(1-\varepsilon)^{1.296}}{a^{2} \varepsilon^{3}},
$$

where $\mu$ is the viscosity of air $\left(1.84 \times 10^{-5} \mathrm{~Pa} \cdot \mathrm{s}\right), \varepsilon$ is the porosity, and $a$ is the radius of the fiber.

2.4. Tortuosity. The following empirical formula was used to calculate tortuosity $(\sigma)$ in terms of porosity. The tortuosity is expressed in [5]

$$
\sigma=1+\frac{(1-\varepsilon)}{(2 \varepsilon)}
$$

2.5. Sound Absorption Measurement. The acoustic properties of the composite sample were measured using a twomicrophone transfer-function method, according to ASTM E-1050-98/ISO 10534-2 standards. The testing apparatus was part of complete acoustic material testing system Brüel \& Kjaer (type 4206, Brüel \& Kjær), as it is seen in Figure 1. A small tube setup was employed to measure different acoustical parameters in the frequency range of $100 \mathrm{~Hz}-$ $6.4 \mathrm{kHz}$. At one end of the tube, a loudspeaker was situated 


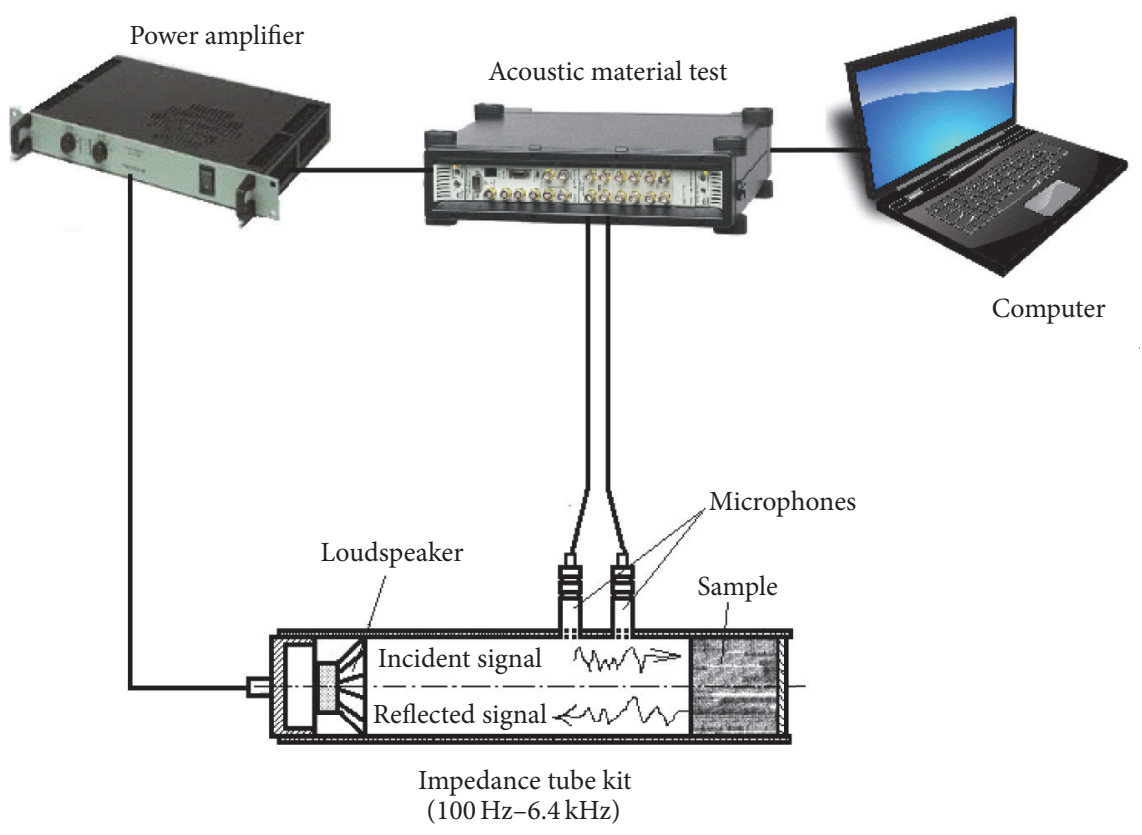

FiguRE 1: Impedance tube kit (type 4206, Brüel \& Kjær).

to act as a sound source and the test material was placed at the other end to measure sound absorption properties. Two acoustic microphones (type 4187, Brüel \& Kjær) were located in front of the sample to record the incident sound from the loudspeaker and the reflected sound from the material. The recorded signals in the analyzer in terms of the transfer function between the microphones were processed using Brüel \& Kjær material testing software to obtain the absorption coefficient of the sample under test. Each set of the experiment was repeated three times in order to have average measurements.

2.6. Mechanical Properties. The tensile and Young's modulus were determined using a Tensilon RTG-1310 universal testing machine with a load cell of $10 \mathrm{kN}$. All the samples of composites were tested after conditioning for $24 \mathrm{~h}$ in a standard testing atmosphere of $70 \%$ relative humidity and $28^{\circ} \mathrm{C}$. According to the ASTMD 3039 standard, a gauge length of $150 \mathrm{~mm}$ and a crosshead speed of $5 \mathrm{~mm} / \mathrm{min}$ were used for tensile testing. The sample size was $250 \mathrm{~mm} \times 25.4 \mathrm{~mm}$ $\times 6 \mathrm{~mm}$. In total 21 samples were tested for each sample condition and the average and standard deviation values were reported.

2.7. Scanning Electron Microscope. The surface morphologies of composites were observed using an Inspect-S50 scanning electron microscope with field emission gun. An accelerating voltage of $10 \mathrm{kV}$ was used to collect SEM images on the surface of the sample. The morphologies of the composites were observed and analyzed via SEM at room temperature. Before testing, the samples were sliced and mounted onto SEM stubs using double-sided adhesive tape. They were gold sputtered for $5 \mathrm{~min}$ to a thickness of approximately
$10 \mathrm{~nm}$ under pressure of 0.1 torr and $18 \mathrm{~mA}$ current to make the sample conductive. SEM micrographs were recorded at different magnifications to ensure clear images.

\section{Results and Discussion}

3.1. Nonacoustic Composites Properties. Large differences were observed in nonacoustical properties of the composite samples, because of their different microstructures as a result of the addition of the $\mathrm{CHF}$ in the polyester. This diversity is very interesting because it provides different porous microstructures and consequently different acoustic properties. Porosity, tortuosity, and flow resistivity values are listed in Table 2.

Increasing the amount of fiber volume fraction in the polyester resin increases the porosity and decreases both tortuosity and air-flow resistivity in the absorbent material (seen Table 2). The porosity value of the sample PF-M was 0.8267, which was higher than those of the other samples used in this study. The presence of lumen in the fiber indicates that the porosity of the sample increases when the number of fibers increases (Figure 2). In other words, the lower value of porosity and higher value of the flow resistivity of the sample can be attributed to the higher volume fraction of polyester resin.

All the composite samples demonstrate an open pore structure wherein the pores are interconnected. This is one of the most important factors for noise absorption because such a structure decreases air-flow resistivity and thus the dissipation of the wave energy in the pores. In these samples, the multiscale fiber structure with the lumen inside fiber bundle has a pore shape, and the pore size can differ by several orders of magnitude (Figures 2(a) and 2(b)). 
TABLE 2: Nonacoustical properties of samples.

\begin{tabular}{lccccc}
\hline Sample & Thickness $(\mathrm{mm})$ & Density $\left(\mathrm{Kg} \cdot \mathrm{m}^{3}\right)$ & $\begin{array}{c}\text { Porosity } \\
\varepsilon\end{array}$ & Air-flow resistivity, $R\left(\right.$ Pa.s $\left.\cdot \mathrm{m}^{-2}\right)$ & $\begin{array}{c}\text { Tortuosity, } \\
\sigma\end{array}$ \\
\hline PF-E & 20 & 640.5 & 0.6474 & 44,980 & 1.272 \\
PF-G & 20 & 383.4 & 0.7053 & 29,353 & 1.208 \\
PF-H & 20 & 304.1 & 0.7247 & 25,424 & 1.190 \\
PF-I & 20 & 244.1 & 0.7457 & 21,576 & 1.171 \\
PF-K & 20 & 198.0 & 0.7582 & 19,568 & 1.160 \\
PF-M & 20 & 158.3 & 0.7954 & 14,435 & 1.128 \\
\hline
\end{tabular}

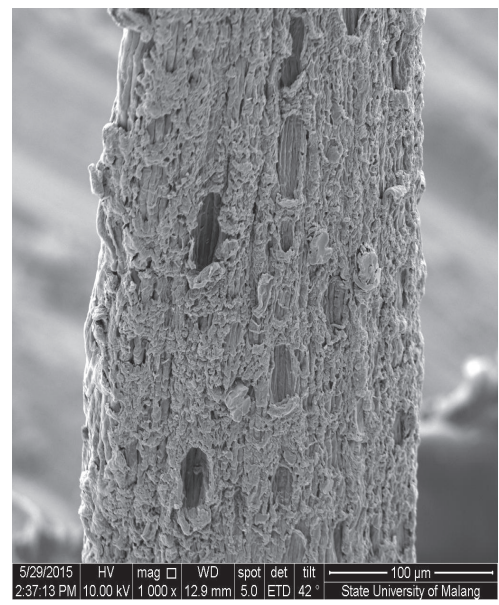

(a)

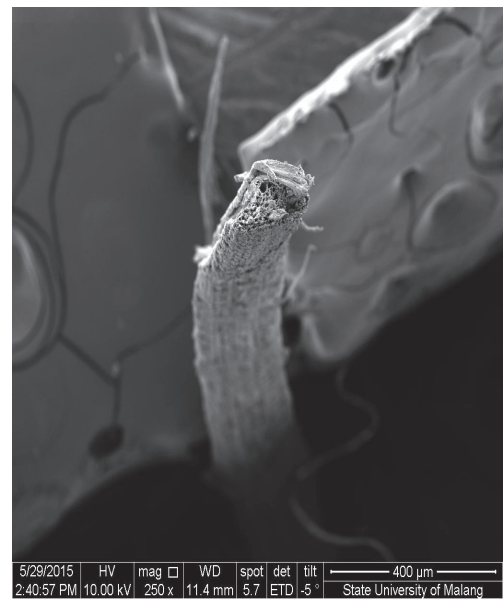

(b)

FIGURE 2: SEM photomicrographs of corn husk fibers $5 \% \mathrm{NaOH}$ treated: (a) surface and (b) cross-sectional features.

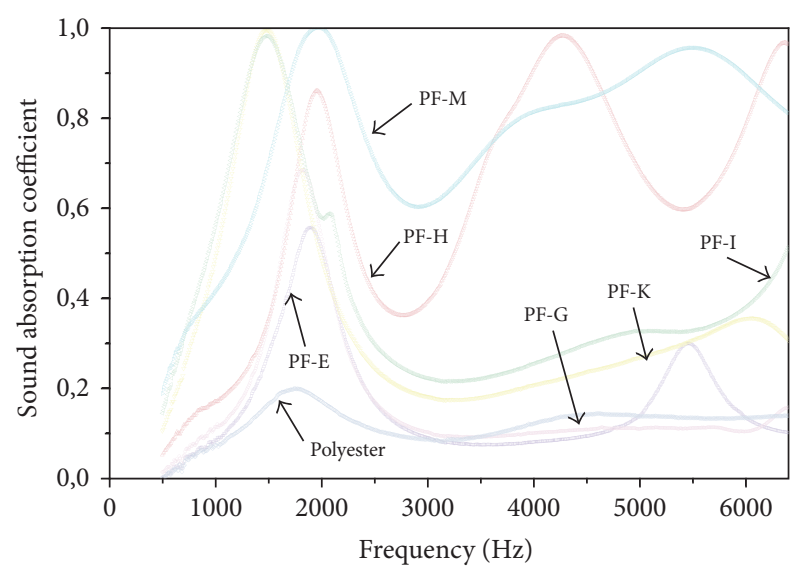

FIGURE 3: The sound absorption coefficients of composite samples.

3.2. Acoustical Properties. The normal sound absorption properties for all samples of CHF-polyester composites are graphically illustrated in Figure 3. The zero value in the $y$ axis indicates perfect sound reflection, and the value of one implies complete sound absorption. These results show that all composite samples demonstrated an increase in sound absorption coefficient in the range of $1 \mathrm{kHz}-2.5 \mathrm{kHz}$. This is because lumen inside the fiber bundle increases the amount of fiber, which results in high absorption coefficient. The additional thermal energy is dissipated more rapidly due to the increased frictional surface area. The sound absorption coefficient of the PF-M sample is therefore correspondingly higher than those of the other samples. The sound waves propagate vibration energy through the air spaces in the individual lumina inside the fiber. A part of this sound energy is converted into heat in the lumina, which is then absorbed by the surrounding walls. The larger the air cavities and lumina inside the fiber, the longer the wavelength of the sound that is absorbed, so more dominant at low frequencies. SEM micrograph analysis (Figures 6(a), 6(c), 6(e), 6(g), 6(i), and $6(\mathrm{k})$ ) illustrates that there are many lumens inside the fiber and continuous channels in the porous structure of polyester composites.

At frequencies above $2 \mathrm{kHz}$, the sound absorption capability of PF-E, PF-G, PF-I, and PF-K samples decreases. The decrease caused by the interface of the fiber/resin and orderly fiber arrangement that cause the higher value of the flow resistivity of the sample makes movements of the sound difficult to pass through the samples. An absorption coefficient is close to zero when the fibers are arranged in a conventional pattern. SEM micrographs (Figure 6) illustrate that there is a distinct interface between fibers and resin in all samples. Interface surfaces between fibers and resin of PFE, PF-G, PF-I, and PF-K samples (Figures 6(b), 6(d), 6(h), 


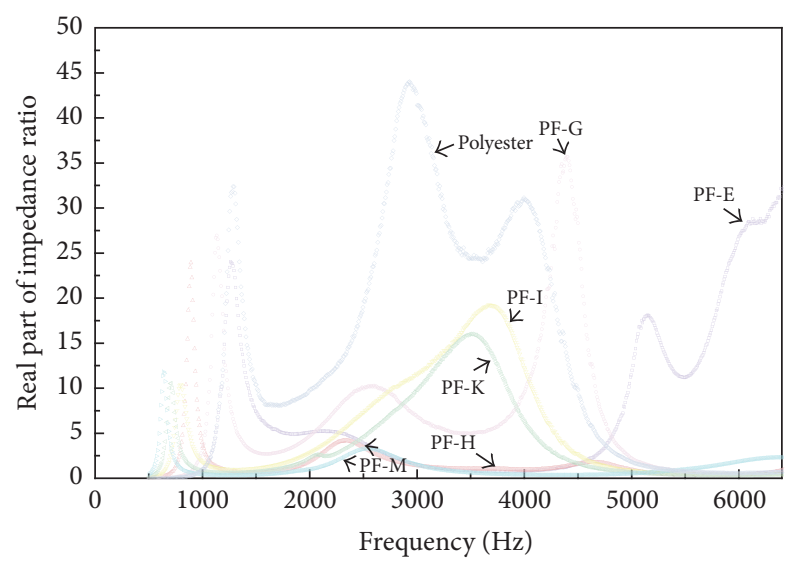

FIGURE 4: The real part of the impedance ratio of different samples.

and $6(\mathrm{j})$, resp.) are quite dense and contain orderly fiber bundles arrangement. Interface strength not only influences composite mechanical property but also influences sound absorption quality. When sufficient amount of resin is used, the interface area between the fibers and the resin is smooth and strong (Figures 6(a) and 6(b)). When the incident sound waves are continuously transmitted onto a composite interface, the sound waves will be reflected and refracted and the acoustic damping phenomena will consume a small amount of energy, reducing heat losses and thus obtaining a lower absorption coefficient at high frequencies. This would also explain why the sound absorption of PF-E is lower than those of sample patterns of composites which are similar.

Sample pure polyester resin (PE) had the absorption coefficient under 0.2. Although polyester may be a valuable option in noise absorption applications, these results discourage its use as a sound-absorbing material.

Figure 3 also shows that the PF-H and PF-M samples demonstrated the ability to absorb sound at high frequencies above $4 \mathrm{kHz}$. This is due to the random distribution of the fiber. The random distribution of the fibers in the fibrous absorbent materials allows the sound waves to hit the lumen of the fiber bundle and strengthen the sound absorption effect; a high absorption coefficient can be obtained. SEM micrographs (Figures 6(e), 6(f), 6(k), and 6(l)) illustrate the random distribution of the fibers in PF-H and PF-M samples.

Figures 4 and 5 show that the real part is the resistance associated with energy losses and the imaginary part is the reactance associated with phase changes, respectively. In this case, we can observe a better performance of PF-H and PF-M samples than other materials studied. Increasing the amount of fiber reduces the number of impedance values and material stiffness. The reduced impedance values increase the fraction of wave energy that can be transmitted through the sample.

Furthermore, sound absorption at lower frequencies (over $1.0-2 \mathrm{kHz}$ ) is desirable for automotive applications because of this frequency range according to noise from the wind, engine running, tires, road, and conversation, thereby making CHF-polyester composites a promising candidate for automotive interior sound absorption.

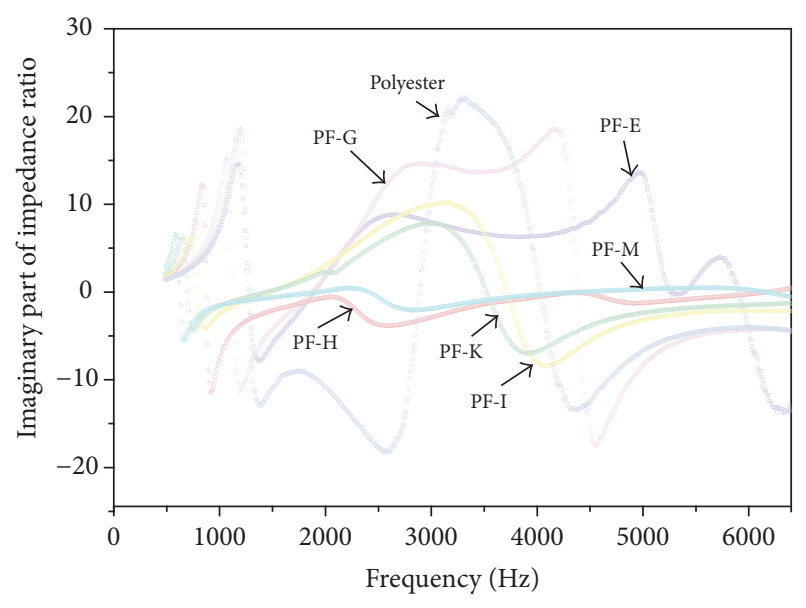

FIGURE 5: The imaginary part of the impedance ratio of samples.

3.3. Mechanical Properties. Theoretically, there should be an interaction between hydrophobic polyester and hydrophilic cellulose. The disappearance of the noncellulose material on the surface of the fiber enables surface interaction with the polyester matrix. The void fraction is mainly formed because the composites have not been consolidated (not sufficiently pressed to form a contiguous solid structure) in order to manufacture composites.

Figures 7 and 8 show that the increase in the fiber volume fraction leads to increase in the tensile strength value and Young's modulus of the composite from $18.81 \pm 8.5$ to $25.73 \pm 3.19 \mathrm{MPa}$. The increase in mechanical strength can be attributed to the bond interface between the fibers and resin. The mechanical properties of the PF-M sample (or composite sample with 20\% resin and $80 \% \mathrm{CHF}$ ) are therefore correspondingly higher than those of the other samples.

For PF-H sample, there was a $12.53 \%$ decrease in the tensile strength values, with a strength value of $20.40 \pm$ 1.1 MPa. The probability of the overlapping of multiple $\mathrm{CHF}$ in composite samples thereby causes the weaker transference of load between fiber and matrix occurring due to the poor interfacial adhesion causing lowering in the mechanical properties. However, the value of the modulus of elasticity of the sample PF-H is higher than that of the material used in this study, contributing to the sound absorption of the sample.

The tensile strength value of the PF-E sample is the lower compared to other samples. This is due to the fiber volume fraction less than the other samples. The tensile strength of the fiber of $237.43 \mathrm{MPa}$ is higher than the tensile strength of the resin.

\section{Conclusions}

In this study, a CHF-polyester sound absorber was proposed and the sound absorption capability of the material was significantly enhanced through the simple method. The presence of a number of lumen structures in the fiber bundle facilitates sound absorption at low frequencies in the range 


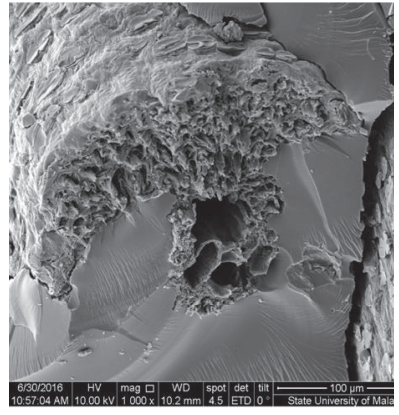

(a)

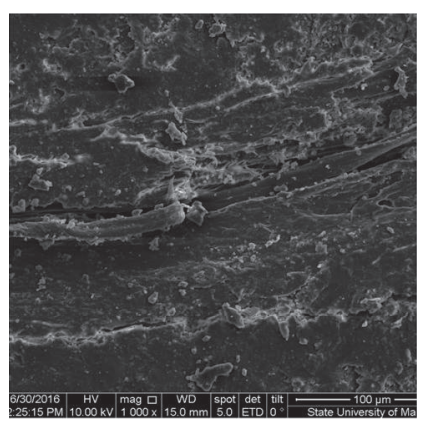

(d)

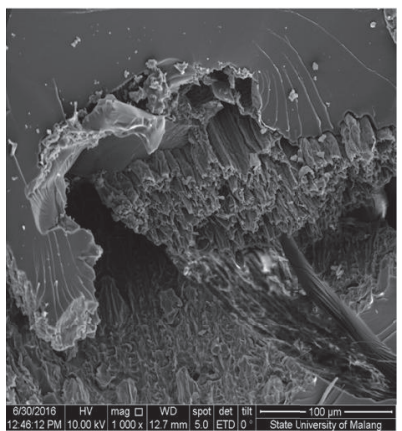

(g)

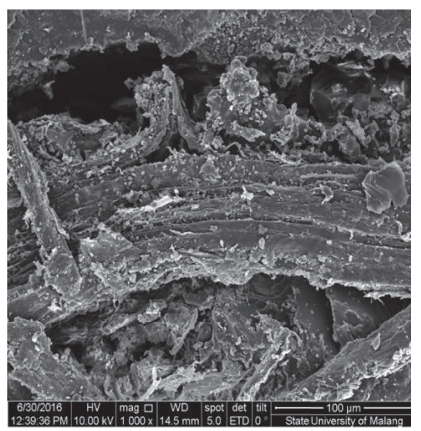

(j)

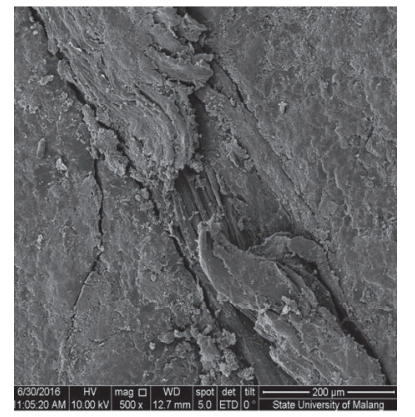

(b)

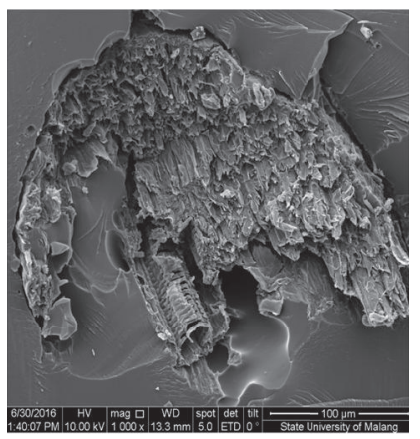

(e)

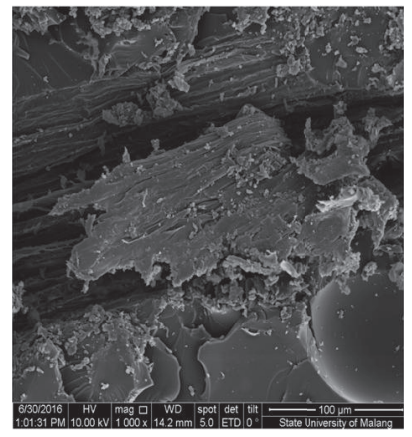

(h)

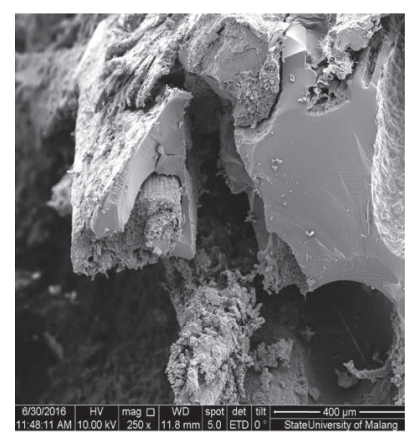

(k)

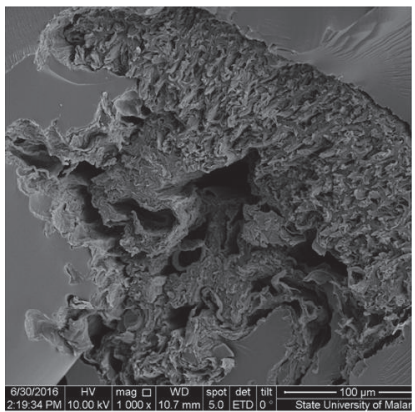

(c)

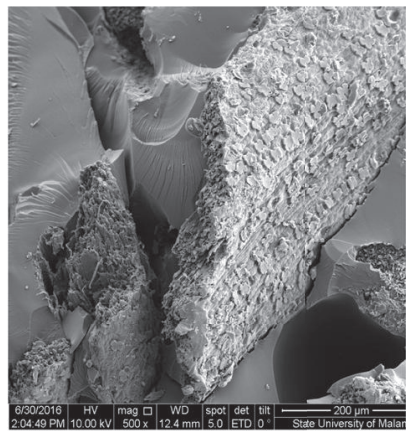

(f)

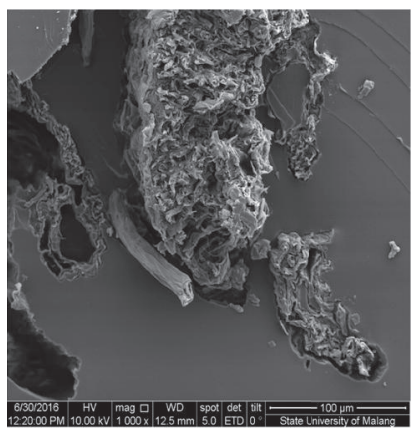

(i)

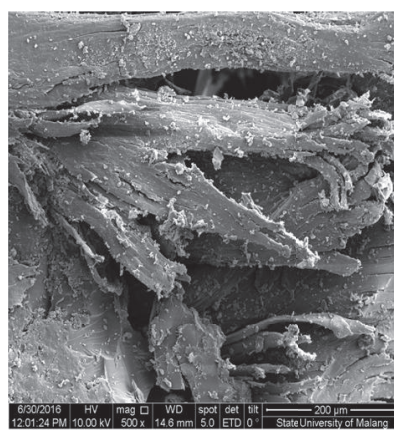

(l)

FIGURE 6: Scanning electron microscope (SEM) images of surfaces of the samples and cross-sectional features of composite samples. (a, b) PF-E, (c, d) PF-G, (e, f) PF-H, (g, h) PF-I, (i, j) PF-K, and (k, l) PF-M. 


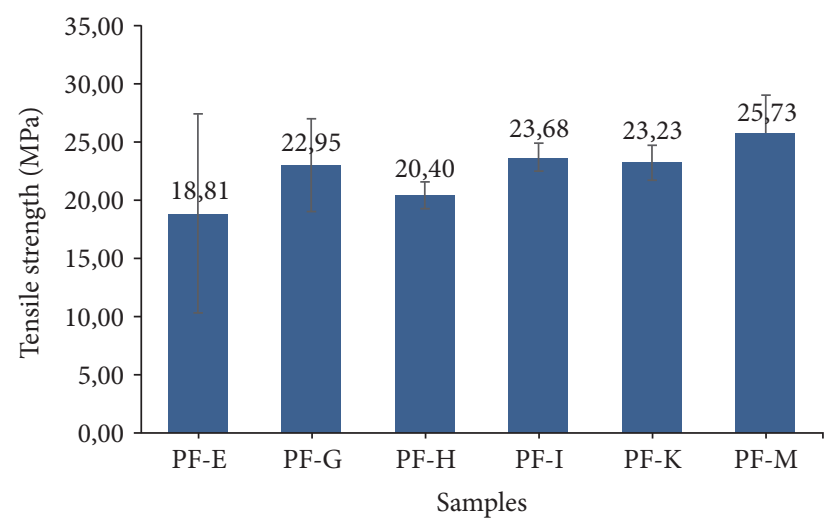

Figure 7: Tensile strength of each sample.

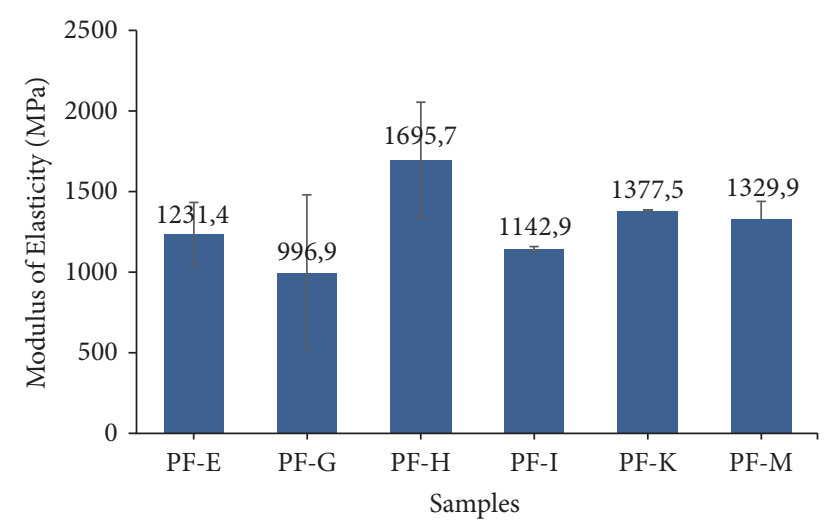

FIGURE 8: Modulus of elasticity of each sample.

of $1 \mathrm{kHz}-2 \mathrm{kHz}$. The interface between the surface of the fiber/resin and orderly arrangement of fibers within the resin of PF-E, PF-G, PF-I, and PF-K samples caused a decrease in the sound absorption properties at frequencies above $2 \mathrm{kHz}$. High frequencies above $4 \mathrm{kHz}$ (PF-H and P F-M samples) are obtained due to the random distribution of the fiber.

Increased resin lowers friction between the fibers, reducing heat losses and subsequently its sound absorption coefficient.

All samples used in this study have the potential to be used as sound-absorbing materials. These results indicate that alternative high-performance sound-absorbing materials could be obtained using CHF, which can solve environmental problems and reduce noise pollution.

\section{Competing Interests}

The authors declare that there is no conflict of interests regarding the publication of this paper.

\section{References}

[1] M. A. Biot, "Theory of propagation of elastic waves in a fluidsaturated porous solid. I. Low-frequency range," The Journal of the Acoustical Society of America, vol. 28, no. 2, pp. 168-178, 1956.
[2] M. A. Biot, "Theory of propagation of elastic waves in a fluidsaturated porous solid. II. Higher frequency range," The Journal of the Acoustical Society of America, vol. 28, no. 2, pp. 179-191, 1956.

[3] M. E. Delany and E. N. Bazley, "Acoustical properties of fibrous absorbent materials," Applied Acoustics, vol. 3, no. 2, pp. 105-116, 1969.

[4] F.-C. Lee and W.-H. Chen, "Acoustic transmission analysis of multi-layer absorbers," Journal of Sound and Vibration, vol. 248, no. 4, pp. 621-634, 2001.

[5] K. Attenborough, "Acoustical characteristics of rigid fibrous absorbents and granular materials," The Journal of the Acoustical Society of America, vol. 73, no. 3, pp. 785-799, 1983.

[6] A. Veerakumar and N. Selvakumar, "A preliminary investigation on kapok/polypropylene nonwoven composite for sound absorption," Indian Journal of Fibre and Textile Research, vol. 37, no. 4, pp. 385-388, 2012.

[7] M. Jailani, M. Nor, and R. Zulkifli, "Effect of compression on the acoustic absorption of coir fiber," America Journal of Applied Sciences, vol. 7, no. 9, pp. 1285-1290, 2010.

[8] R. Zulkifli, Zulkarnain, and M. J. M. Nor, "Noise control using coconut coir fiber sound absorber with porous layer backing and perforated panel," American Journal of Applied Sciences, vol. 7, no. 2, pp. 260-264, 2010.

[9] D. Chen, J. Li, and J. Ren, "Study on sound absorption property of ramie fiber reinforced poly(L-lactic acid) composites: morphology and properties," Composites Part A: Applied Science and Manufacturing, vol. 41, no. 8, pp. 1012-1018, 2010.

[10] A. Putra, Y. Abdullah, H. Efendy, W. M. F. W. Mohamad, and N. L. Salleh, "Biomass from paddy waste fibers as sustainable acoustic material," Advances in Acoustics and Vibration, vol. 2013, Article ID 605932, 7 pages, 2013.

[11] L. P. Bastos, G. D. S. V. De Melo, and N. S. Soeiro, "Panels manufactured from vegetable fibers: an alternative approach for controlling noises in indoor environments," Advances in Acoustics and Vibration, vol. 2012, Article ID 698737, 9 pages, 2012.

[12] T. Koizumi, N. Tsujiuchi, and A. Adachi, "The development of sound absorbing materials using natural bamboo fibers," High Performance Structures and Materials, vol. 4, pp. 157-166, 2002.

[13] E. Jayamani and S. Hamdan, "Sound absorption coefficients natural fibre reinforced composites," Advanced Materials Research, vol. 701, pp. 53-58, 2013.

[14] M. Vašina, D. C. Hughes, K. V. Horoshenkov, and L. Lapčík Jr., "The acoustical properties of consolidated expanded clay granulates," Applied Acoustics, vol. 67, no. 8, pp. 787-796, 2006.

[15] F. P. Mechel, Formulas of Acoustics, Springer, Berlin, Germany, 2nd edition, 2008.

[16] R. Maderuelo-Sanz, A. V. Nadal-Gisbert, J. E. Crespo-Amorós, and F. Parres-García, "A novel sound absorber with recycled fibers coming from end of life tires (ELTs)," Applied Acoustics, vol. 73, no. 4, pp. 402-408, 2012. 


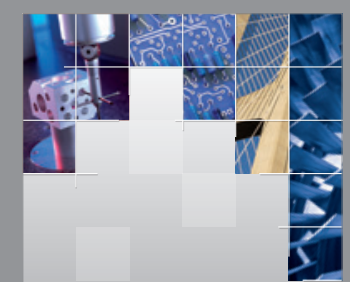

\section{Enfincering}
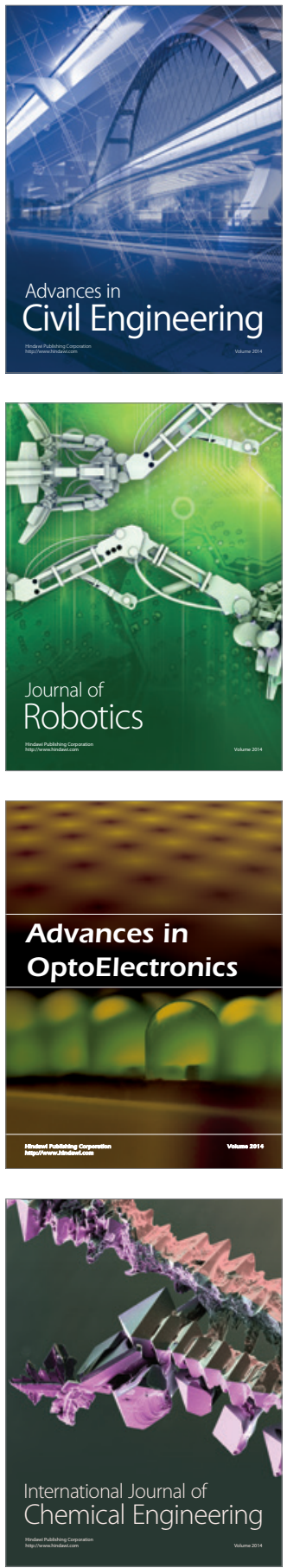

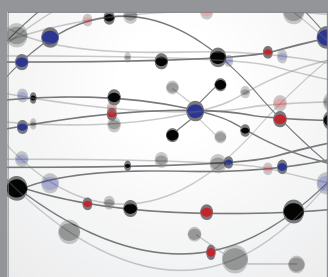

The Scientific World Journal

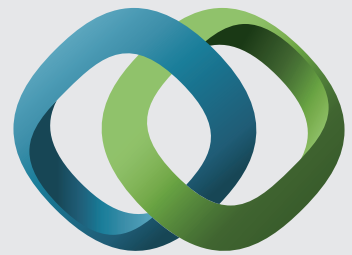

\section{Hindawi}

Submit your manuscripts at

https://www.hindawi.com
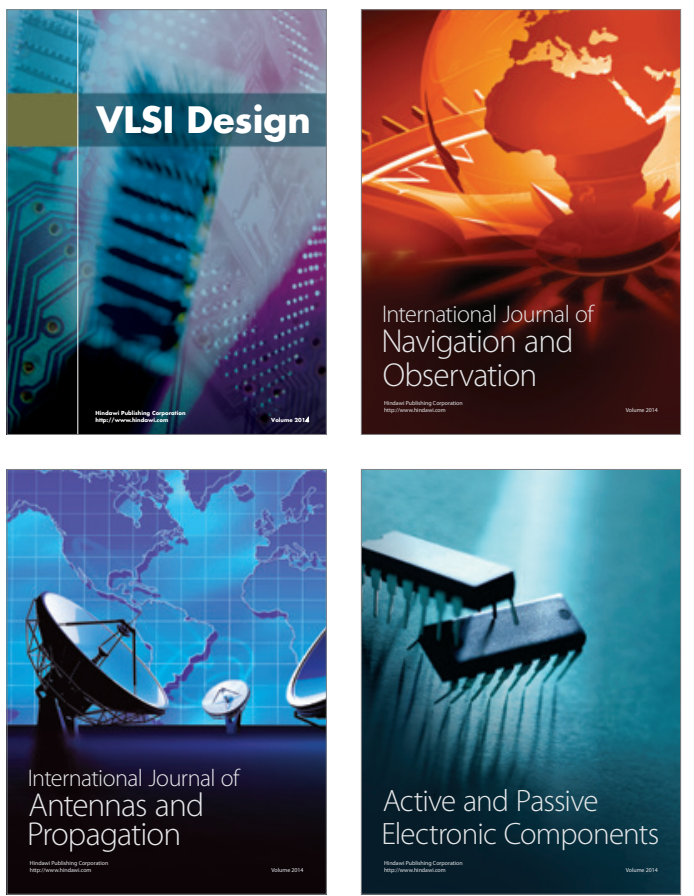
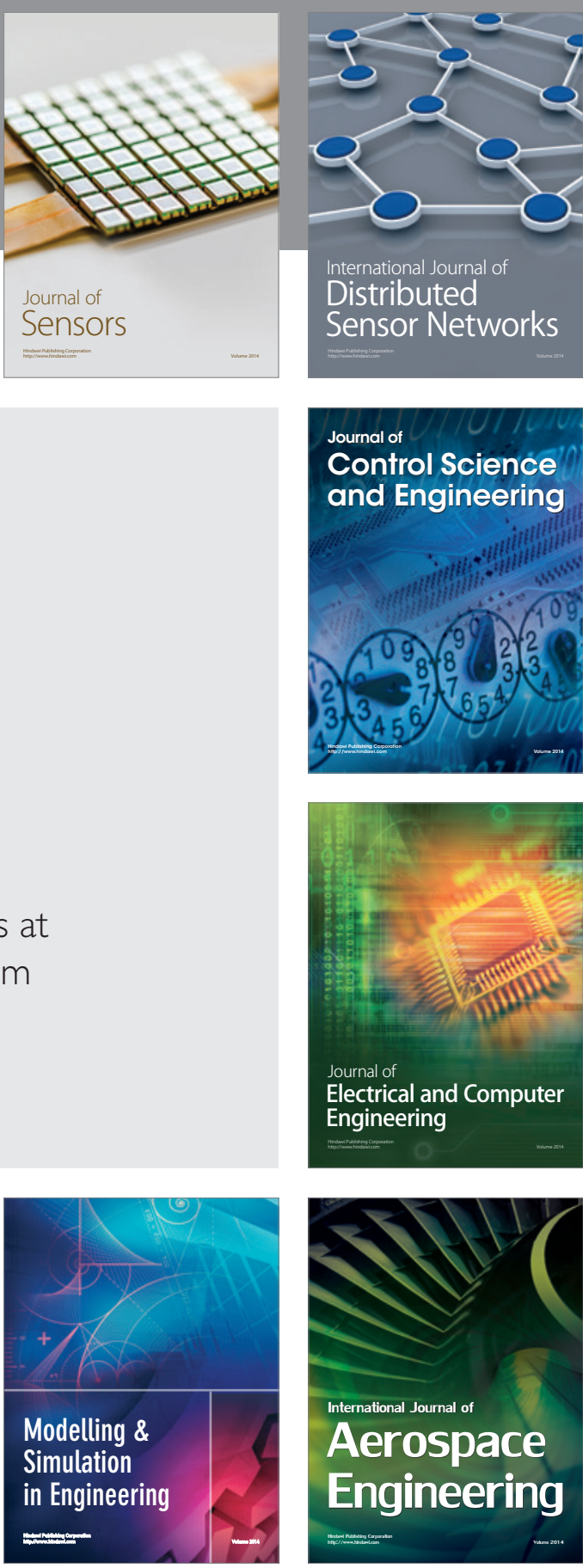

International Journal of

Distributed

Sensor Networks

$-$

Joumal of

Control Science

and Engineering
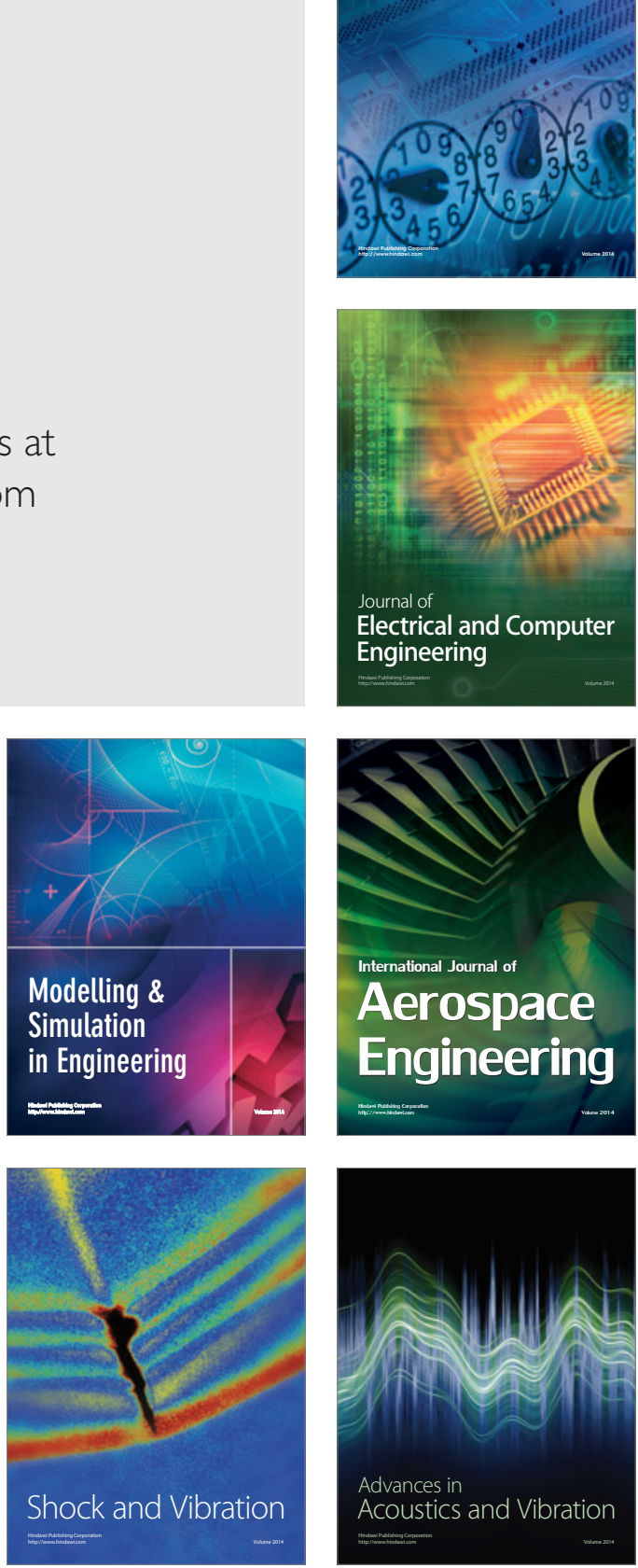